\title{
Evaluation of the Redox State of Wistar Rats Submitted to High-Fat Diet Supplemented With Infusion of Ilex paraguariensis
}

\author{
Clédia Flores Silva1, Patrícia Nardin², Mateus Grings ${ }^{2}$, Julia Neitzel Uecker ${ }^{1}$, Jenifer Heller \\ Cerqueira $^{1}$, Joao Alvarado Rincón ${ }^{3}$, Renata Torres Abib ${ }^{1}$, Augusto Schneider ${ }^{4}$, Carlos \\ Castilho Barros ${ }^{4}$, Robson Andreazza ${ }^{5}$, Simone Pieniz ${ }^{* 1}$ \\ ${ }^{1}$ Universidade Federal de Pelotas - Faculdade de Nutrição - Pelotas, Rio Grande do Sul, Brazil; ${ }^{2}$ Universidade \\ Federal do Rio Grande do Sul - Faculdade de Farmácia - Porto Alegre, Rio Grande do Sul, Brazil; ${ }^{3}$ Universidade \\ Federal de Pelotas - Faculdade de Veterinária - Pelotas, Rio Grande do Sul, Brazil; ${ }^{4}$ Universidade Federal de \\ Pelotas - Centro de Engenharias - Pelotas, Rio Grande do Sul, Brazil; ${ }^{5}$ Universidade Federal de Pelotas - Centro \\ de Engenharias - Pelotas, Rio Grande do Sul, Brazil
}

\begin{abstract}
This study aimed to evaluate the effect of Ilex paraguariensis infusion on redox state of Wistar rats submitted to high-fat and standard diet. Glutathione determination and lipid peroxidation in the hippocampus tissues and liver was performed, as well as the analysis of gene expression of superoxide dismutase, catalase and glutathione peroxidase by real-time polymerase chain reaction. The results from hippocampus showed that the groups fed with standard diet exhibited significant reduction of lipid peroxidation when supplemented with Ilex paraguariensis. The analysis from glutathione determination in the hippocampus showed a significant increase in glutathione activity in the group treated with high-fat diet and Ilex paraguariensis. In the liver, results showed no significant difference in both glutatione and lipid peroxidation analisys. Gene expression of superoxide dismutase, catalase and glutathione peroxidase showed that there was significant difference in the groups treated with high-fat diet and Ilex paraguariensis. In summary, the Ilex paraguariensis showed substantial potential for antioxidant activities.
\end{abstract}

Keywords: Ilex paraguariensis, bioactive compounds, oxidative stress, antioxidant defense.

*Author for correspondence: nutrisimone@yahoo.com.br 


\section{INTRODUCTION}

In a regular cell, there is a balance between formation and removal of free radicals. However, this balance can be induced for more formation of free radicals or reduced the levels of antioxidants. This is called as "oxidative stress" and can result in serious cell damage if the stress is massive and prolonged. Oxidative stress plays a major role in the development of chronic and degenerative diseases such as cancer, arthritis, aging and autoimmune disorders ${ }^{1}$. Reactive oxigen species (ROS) are produced from molecular oxygen as a result of regular cellular metabolism. ROS can be divided into two groups: free radicals and nonradicals. Molecules containing one or more unpaired electrons and thus giving reactivity to the molecule are called free radicals $^{2}$.

The most important oxygen-containing free radicals in many disease states are the hydroxyl radical, superoxide anion radical, hydrogen peroxide, oxygen singlet, hypochlorite, nitric oxide radical, and peroxynitrite radical. These are highly reactive free radicals, capable in the nucleus, and in the membranes of cells of damaging biologically relevant molecules such as DNA, proteins, carbohydrates, and lipids ${ }^{3}$.

Antioxidant activity denotes the ability of a bioactive compound to maintain cell structure and function by effectively clearing free radicals, inhibiting lipid peroxidation reactions, and preventing other oxidative damages ${ }^{4}$. Mechanisms of endogenous antioxidant defence are not always sufficient to fully scavenge free radicals of the body and dietary components that have antioxidant properties such as tea flavonoids are therefore necessary to supplement the activity of endogenous antioxidants. One of the major endogenous antioxidants in the body is glutathione (GSH). GSH has many functions, one of them is the protection of the cells against oxidative damage by scavenging free radicals and peroxides produced during regular cellular respiration, which would otherwise oxidise proteins, lipids and nucleic acids 5 .

Antioxidant molecules are in fact nucleophilic and reductant molecules able to react with oxidants, which they are generally electrophiles, giving them one or two electrons. In order to minimize or reverse the damage caused by oxidative processes from cafeteria diets, several plants have been studied to demonstrate the preventive antioxidant role. Plants containing phenolic compounds have been the subject of several studies on the prevention and treatment of many health problems ${ }^{6}$. Yerba mate (Ilex paraguariensis) is widely consumed in South America, including Argentina, Brazil, Uruguay and Paraguay. It is a herbal tea beverage that is made from the leaves of the tree Ilex paraguariensis St. Hilare (Aquifoliaceae) ${ }^{7}$. In current years, the importance of phenolic compounds in biological activity of Ilex paraguariensis has been highlighted. The phenolic compounds of major importance in Ilex paraguariensis refer to caffeoyl derivatives, mainly monocaffeoyl quinic isomers (3-O-caffeoyl quinic or neochlorogenic acid, 5O-caffeoyl quinic or chlorogenic acid and 4-O-caffeoyl quinic or cryptochlorogenic acid) and dicaffeoyl quinic isomers (3,4-dicaffeoylquinic acid, 3,5- dicaffeoylquinic acid and 4,5-dicaffeoylquinic acid $)^{8}$.

Therefore, the Ilex paraguariensis extract possibly contain in your composition phenolic compounds and/or antioxidants that can contribute to the reduction of oxidative damage in the cells. It was investigated in this study the ability of these substances to inhibit in vivo oxidative processes as 
well as their potential redox. The interest in the use of bioactive substances that have the ability to reduce oxidative stress mediated by reactive species has increased considerably, particularly through the use of antioxidant food source such as vitamins $\mathrm{C}$ and $\mathrm{E}$, flavonoids and other phenolic compounds, like Ilex paraguariensis. Thus, this study aimed to evaluate the redox state of Wistar rats (Rattus Novergicus) submitted to high-fat diet supplemented with infusion of Ilex paraguariensis.

\section{MATERIALS AND METHODS}

\section{Experimental conditions and monitoring}

This study was approved by the Ethics Committee on Animal Experiments (Protocol $n^{\circ}$ 1641) of Federal University of Pelotas (UFPEL). For this study, 32 female Wistar rats (Rattus Novergicus) with 60 days old were used. The rats were kept in groups of four animals at polypropylene boxes in ventilated cabinets, with controlled temperature and relative humidity conditions $\left(23^{\circ} \mathrm{C}\right.$ $\pm 1^{\circ} \mathrm{C}$ and $65-75 \%$ humidity), and exposed to a 12 hour light/dark cycle. After five days of adaptation, the rats were randomly divided into four groups ( $\mathrm{n}=8$ rats per group), as follows: standard diet ( $4 \%$ fat) + water $a d$ libitum (SW); standard diet (4\% fat) + Ilex paraguariensis extract ad libitum (SIP); high-fat diet (25\% fat, $1 \%$ cholesterol and $0.1 \%$ cholic acid) + water ad libitum (HFW); high-fat diet (25\% fat, $1 \%$ cholesterol and $0.1 \%$ cholic acid) + Ilex paraguariensis extract ad libitum (HFIP).

The standard (4\% fat content) and high-fat diets (25\% fat content, $1 \%$ cholesterol and $0.1 \%$ cholic acid) were prepared in the laboratory, as recommended by the American Institute of Nutrition - AIN93 - M for rodents ${ }^{9}$. The commercial sample of the Ilex paraguariensis used in this study was randomly selected in a supermarket in the city of Pelotas - RS, a grounded fine type without sugar was used. The same brand and batch of Ilex paraguariensis was used throughout the experiment period, guaranteeing product homogeneity. The Ilex paraguariensis extract was prepared in a $10 \%$ concentration and $70^{\circ} \mathrm{C}$ temperature, resembling the human ingestion. The infusion of the extract was performed for 20 minutes and the extract was not washed.

The body weight was measured weekly using an electronic scale (JH2102/Bioprecisa, Curitiba, Brazil) and food intake was monitored daily during the 34 days of the study. Rats were killed at $34^{\text {th }}$ day, after a 8 hours fasting, following the ethical principles in animal experimentation used by the Brazilian College of Animal Experimentation ${ }^{10}$.

\section{Thiobarbituric acid-reactive species}

Thiobarbituric acid-reactive species (TBARS) were determined according to the method described by Esterbauer and Cheeseman ${ }^{11}$. Briefly, $300 \mu \mathrm{l}$ of $10 \%$ of trichloroacetic acid was added to $150 \mu \mathrm{l}$ of samples of liver and/or hippocampus and centrifuged at $1000 \times \mathrm{g}$ for $10 \mathrm{~min}$ at $4^{\circ} \mathrm{C}$. Three hundred microliters of the supernatant was transferred to a test tube and incubated with $300 \mu \mathrm{l}$ of $0.67 \%$ of thiobarbituric acid (Sigma-Aldrich) (in $7.1 \%$ sodium sulfate) at $100^{\circ} \mathrm{C}$ for $25 \mathrm{~min}$. The mixture was allowed to cool on water bath for $5 \mathrm{~min}$. The resulting pink stained TBARS were determined in a spectrophotometer at $535 \mathrm{~nm}$. Calibration curve was performed using 
1,1,3,3-tetramethoxypropane subjected to the same treatment as that of the supernatants. TBARS were calculated as nmol TBARS/mg protein.

\section{Glutathione content (GSH)}

GSH content was determined as described by Browne and Armstrong ${ }^{12}$. Briefly, slices of liver and hippocampus were homogenized in sodium phosphate buffer (0.1 M, pH 8.0) containing $0.005 \mathrm{M}$ EDTA and protein was precipitated with $1.7 \%$ meta-phosphoric acid. Supernatant was assayed with o-phthaldialdeyde $(1 \mathrm{mg} / \mathrm{mL})$ at room temperature for $15 \mathrm{~min}$. Fluorescence was measured using excitation and emission wavelengths of 350 and 420 $\mathrm{nm}$, respectively. GSH concentrations were calculated as $\mathrm{nmol} / \mathrm{mg}$ protein.

\section{Gene expression by real-time PCR}

To determine the gene expression, samples of liver was collected and immediately stored at $-80^{\circ} \mathrm{C}$. The samples were homogenized with Qiazol (Qiagen, Valencia, USA), and total RNA was isolated and purified following the Qiazol protocol. The quality of RNA was assessed by electrophoresis in agarose gel. The reverse transcription reactions were performed using $1 \mu \mathrm{g}$ of RNA with a reverse transcription kit containing RNase inhibitor (Applied Biosystems, Foster City, USA) in a volume of $10 \mu \mathrm{L}$. Real-time PCR was performed to assess the expression of the target genes Copper/Zinc Superoxide Dismutase (CU/ZN-SOD); Catalase (CAT); Glutathione peroxidase (GPx) and internal control ( $\beta$-actin) (Table 1). PCR reactions were performed in triplicate in a volume of $12 \mu \mathrm{L}$ using SYBR Green Mastermix (Applied Biosystems) and the fluorescence was quantified in the Eco Real Time (Illumina, San Diego, California, USA). For each test, 40 cycles were carried out and a dissociation curve was included at the end of the reaction in order to verify the amplification of a single PCR product. Data is reported as folds over the minimum according to Masternak et al. ${ }^{13}$. Each assay plate included a negative control with water.

Table 1. Oligonucleotides used in the analysis of gene expression by real-time PCR.

\begin{tabular}{llccc}
\hline \multicolumn{1}{c}{ Oligonucleotides } & \multicolumn{1}{c}{ Sequence (5'-3') } & Target gene & $\begin{array}{c}\text { Product } \\
(\mathbf{p b})\end{array}$ & $\begin{array}{c}\text { Acess number } \\
\text { GenBank }\end{array}$ \\
\hline$\beta$-actin-F (F) & TCACCACCACAGCCGAGAGA & $\beta$-actin & 72 & NM_205518 \\
$\beta$-actin-R $(\mathrm{R})$ & CGAAATCCAGTGCGACGTAGC & & & \\
CU/ZN-SOD $(\mathrm{F})$ & GGTGGTCCACGAGAAACAAG & Cu/Zn-SOD & 98 & AC_000028.1 \\
CU/ZN-SOD (R) & CAATCACACCACAAGCCAAG & & & \\
CAT $(\mathrm{F})$ & GAATGGCTATGGCTCACACA & CAT & 100 & AC_000037.1 \\
CAT $(\mathrm{R})$ & CAAGTTTTTGATGCCCTGGT & & & \\
GPx $(\mathrm{F})$ & GGTGTTCCAGTGCGCAGAT & GPx & 22 & AC_000042.1 \\
GPx $(\mathrm{R})$ & AGGGCTTCTATATCGGGTTCGA & & & \\
\hline
\end{tabular}




\section{Statistical analysis}

Data was analyzed using two-way analysis of variance (Two-way ANOVA) and Tukey's test at 5\% significance level for comparison of means, using Assistat 7.7 beta. The effects of the diet, supplementation with mate and their interaction were tested. When the interaction was significant individual groups were compared by t-test.

\section{Results and Discussion}

We analyzed in this study two diets with aiming to evaluate the effect of the healthy diet (standard diet) and with elevated percentage of fat (high-fat diet) and the possible antioxidant properties of mate tea on these diets, since yerba mate possesses many bioactive compounds, such as caffeine, phenolic acids, and saponins, which are absorbed by the body and may act as antioxidants. The results of the lipid peroxidation (TBARS) in the hippocampus of the rats showed significant difference between the group fed with standart diet (Fig. $1 \mathrm{~A})$, demonstrating significant reduction $(\mathrm{p}<0.05)$ of lipid peroxidation in the group supplemented with Ilex paraguariensis compared to the group supplemented water. However, when compared the standard diet and highfat diet, it was observed that the animals fed with a high-fat diet and with/without Ilex paraguariensis showed significantly lower levels $(p<0.05)$ of lipid peroxidation compared to animals receiving standard diet, but it was not shown significant difference beteween the both high-fat diet groups. Analyzing the results of lipid peroxidation in the liver, there was no difference among all the groups (Fig. 1B). 

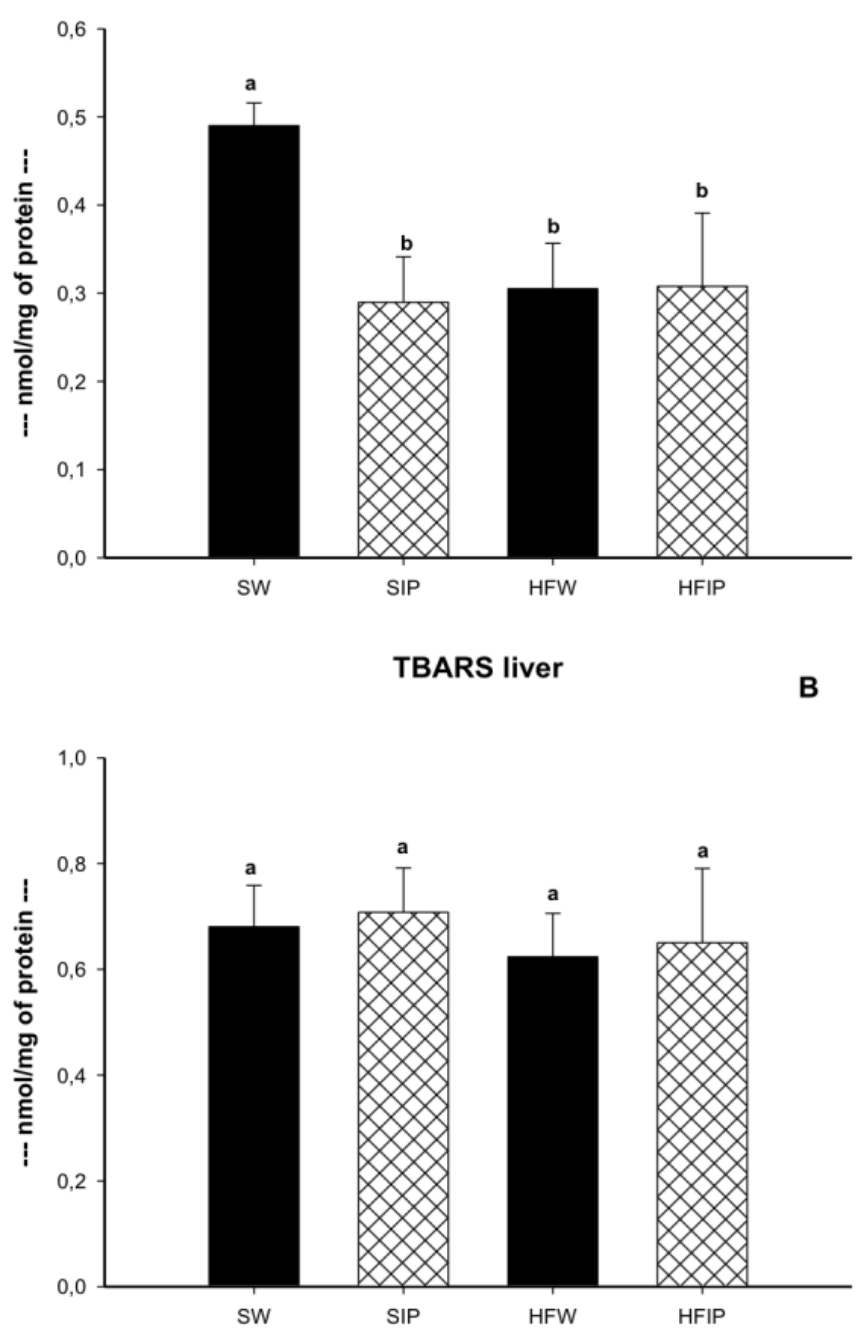

Figure. 1. TBARS levels of evaluation in the hippocampus (A) and liver (B) of rats submitted to high-fat diet treated with aqueous extract of Ilex paraguariensis. SW: standard diet (4\% fat) + water ad libitum; SIP: standard diet (4\% fat) + Ilex paraguariensis extract ad libitum; HFW: high-fat diet + water ad libitum; HFIP: high-fat diet + Ilex paraguariensis extract ad libitum. Values with the same letters did not show statistically significance differences between groups in according to analysis of variance (ANOVA) $(\mathrm{p}<0.05)$.

It can be verified that the high-fat diet promoted increased levels of lipid peroxidation in the hippocampus. It is suggested that the higher degree of unsaturation of the high-fat diet has influenced the increased production of these metabolites of oxidative stress. Increased consumption of polyunsaturated fatty acids without adequate antioxidant protection can lead to lipid peroxidation in vivo ${ }^{14}$.

The brain has reduced capacity for cell regeneration in comparison to other tissues, because it is metabolically very active, so, it is believed to be particularly susceptible to the damaging effects of oxidative stress ${ }^{15}$. It is known that oxidative stress is defined as an imbalance between production of oxygen-free radicals and antioxidant defense mechanisms, leading to a cascade of reactions in which lipids, proteins, and DNA may be damaged ${ }^{16}$. According to Park et al. ${ }^{17}$ high-fat diet consumption led to increased brain 
oxidative damage through induction of lipid peroxidation in the hippocampus of mice, as we observed in the current study.

Growing evidence suggests that the major killers such as cardiovascular disease and cancer, can be prevented or delayed to some extent by dietary changes, such as a reduction in fat intake and increased consumption of fruits, grains, and vegetables ${ }^{18}$. This study obtained several compounds from a healthy diet that may act to diminish oxidative damage in vivo. Since our endogenous antioxidant defenses are not $100 \%$ efficient, it is reasonable to propose that dietary antioxidants are important in decreasing the cumulative effects of oxidative damage over the long human lifespan, and that they account for some of the beneficial effects obtained by ingestion of natural foods, such as Ilex paraguariensis ${ }^{19}$.

A study with Ilex paraguariensis demonstrated that chlorogenic and caffeic acids and the flavonoid rutin present in aqueous extracts of Ilex paraguariensis samples contributed directly to the antioxidant activity, by preventing lipid peroxidation ${ }^{20}$. Oxidation of low density lipoprotein (LDL) induced by free radicals, i.e., plays an important role in atherosclerosis. In this context, aqueous extracts of Ilex paraguariensis have demonstrated the ability to inhibit LDL oxidation, thereby inhibiting lipid peroxidation, and hence the oxidation of $\mathrm{DNA}^{21,7}$. The results corroborate with these researchers which demonstrated inhibition of lipid peroxidation in the standard group supplemented with Ilex paraguariensis.

This study evaluated the content of GSH, an important antioxidant endogenous tripeptídeo non-enzymatic. According to the results, there was no effect between standard diet group when analyzed the activity in the hippocampus (Fig. 2A). However, when analyzing the group supplemented high-fat diet and Ilex paraguariensis it was observed significant difference $(\mathrm{p}<0.05)$, compared to the group received high-fat diet and water, demonstrating an increase in GSH activity in the animals treated with Ilex paraguariensis. When analyzing the GSH levels in the liver it was observed no significant difference among all the groups (Fig. 2B). 

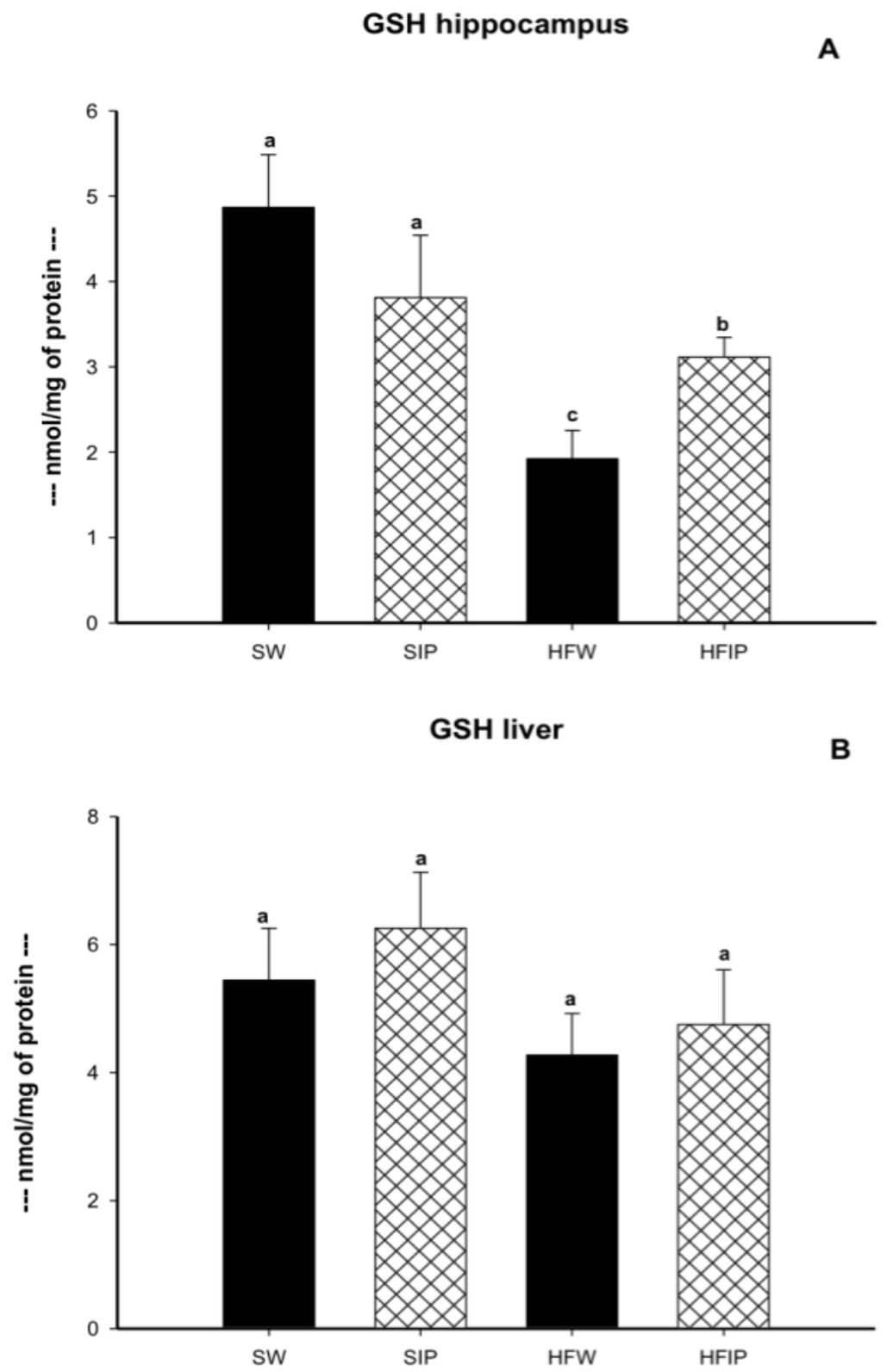

Figure. 2. Analysis of non-enzymatic redox state in the hippocampus (A) and liver (B) of rats submitted to high-fat diet treated with Ilex paraguariensis extract. SW: standard diet (4\% fat) + water ad libitum; SIP: standard diet (4\% fat) + Ilex paraguariensis extract ad libitum; HFW: high-fat diet + water ad libitum; HFIP: high-fat diet + Ilex paraguariensis extract ad libitum. Values with the same letters did not show statistically significance differences between groups in according to analysis of variance (ANOVA) $(\mathrm{p}<0.05)$.

GSH is considered the most abundant molecule among endogenous antioxidants. It is a reduced peptide consisting of three-residues $(\gamma-\mathrm{L}-$ glutamyl-L-cysteinyl glycine) which can donate an eléctron with the consequence that two electron donating GSH molecules form oxidized (GSSG). In humans, GSH is present in high concentration (1-10 mM) which allows to scavenge ROS either directly or indirectly, such as an antioxidant, reacting with ROS, reactive nitrogen species (RNS) and radicals produced in association with electron transport, xenobiotic metabolism and inflammatory responses $^{22,23}$. The GSH shows detoxifies hydrogen peroxide and lipid 
peroxides by action of glutathione peroxidase (GSH-Px), and donates its electron from hydrogen peroxide $\left(\mathrm{H}_{2} \mathrm{O}_{2}\right)$ to reduce it into $\mathrm{H}_{2} \mathrm{O}$ and $\mathrm{O}_{2}{ }^{24}$. Analysing the cellular antioxidant defences, GSH concentration is a sensitive indicator of the cellular redox status in cells. There are studies showing the reduction of the tripeptide GSH as a consequence of oxidative stress and its increase after phenolic ingestion ${ }^{25}$.

According to Lahouel et al. ${ }^{26}$, phenolic antioxidants may play a role in the preservation of GSH levels, by lowering its oxidation and even promoting an increase of GSH synthesis. GSH is the major cellular thiol participating in cellular redox reactions and can directly scavenge free radicals or act as a substrate for GPx during the detoxification of hydrogen peroxide and lipid hydroperoxides. Currently, Boaventura et al. ${ }^{27}$ demonstred that ingestion of $1 \mathrm{~L}$ of roasted Ilex paraguariensis promoted significant increase in blood levels of GSH in dyslipidemic individuals. Although, roasted Ilex paraguariensis infusion has a lower content of phenolic compounds than green Ilex paraguariensis infusion ${ }^{28}$, such difference was not high enough to influence the extent of GSH enhancement.

In the present study, it was evaluated the gene expression of SOD, CAT and GPx in the liver of rats, which have able to scavenger the excess of reactive oxygen species in the body. It was evaluated in the likewise if the administration of high-fat diet and/or Ilex paraguariensis intervention could modulate the expression of genes involved in the production of antioxidant enzymes SOD, CAT and GPx. The results from the gene expression of SOD, CAT and GPx showed that there was significant difference $(\mathrm{p}<0.05)$ in the animals treated with high-fat diet and Ilex paraguariensis compared with the animals treated with the high-fat diet and water (Fig. 3A; 3B and 3C), demonstrating increase of the expression of this enzymes in the presence of Ilex paraguariensis. Interestingly, when analyzing the results of gene expression between different diets, it was shown that the expression of enzymes of SOD and CAT, both decreased in the animals after high-fat diet supplementation (Fig. 3A and 3B). 

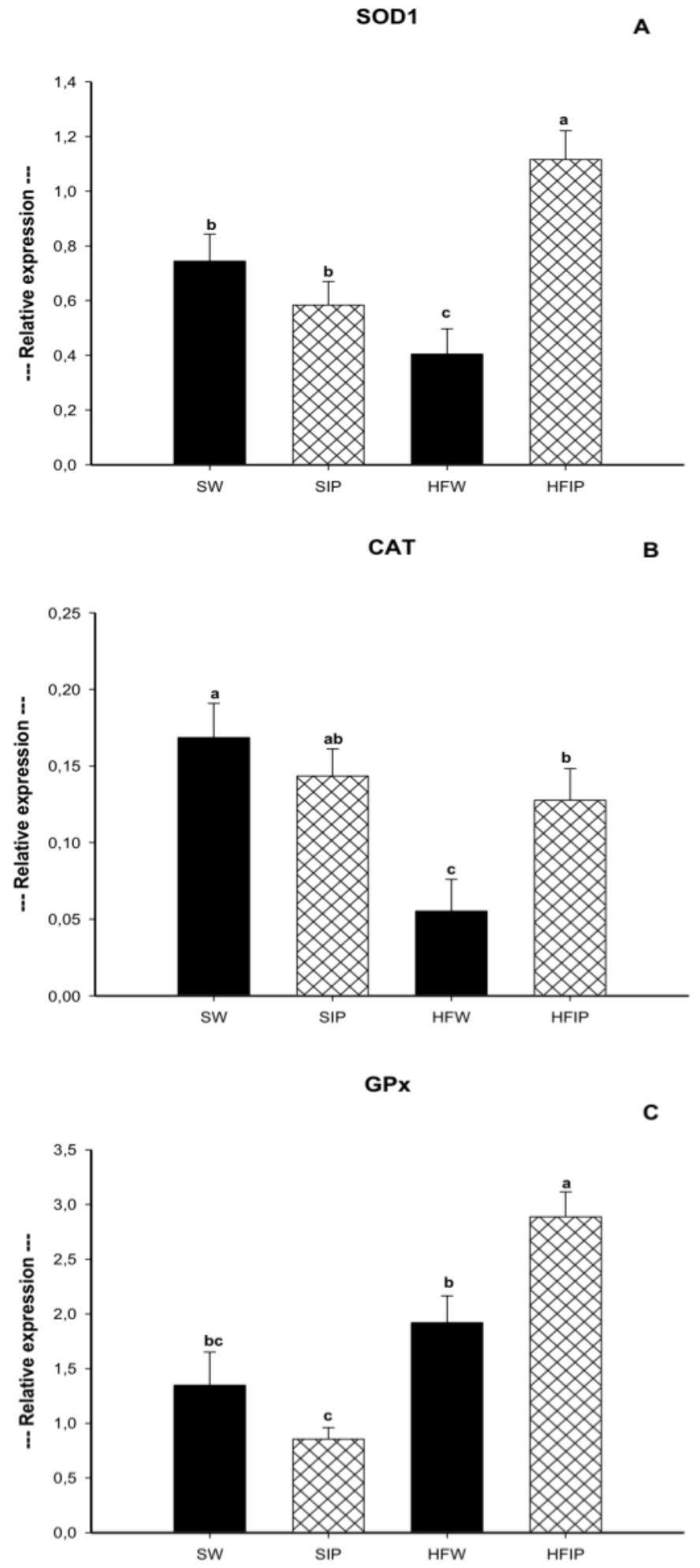

Figure. 3. Yerba Mate extract intake effect of gene expression of SOD (A), CAT (B) and GPx (C) in liver of rats supplemented with standard and high-fat diet. SW: standard diet (4\% fat) + water ad libitum; SIP: standard diet (4\% fat) + Ilex paraguariensis extract ad libitum; HFW: high-fat diet + water ad libitum; HFIP: high-fat diet + Ilex paraguariensis extract ad libitum. Values with the same letters did not show statistically significance differences between groups in according to analysis of variance (ANOVA) (p $<0.05)$. 
It is well established in the literature that the balance between the speed of production and activity of these enzymes (SOD, CAT and GPx) determines the concentrations of free radicals in the body. CAT and GPx function is to convert the $\mathrm{H}_{2} \mathrm{O}_{2}$ in $\mathrm{H}_{2} \mathrm{O}$ generated by SOD during the dismutation reaction of superoxide anion ${ }^{20}$. However, there is a lack of studies that have evaluated the consumption of Ilex paraguariensis extract and the gene expression of endogenous antioxidant enzymes (SOD, CAT and GPx). It presupposes that the antioxidant properties possibly relates to the high levels of phenolics present in the Ilex paraguariensis extract which would be able to chelate metals sequestering capacity and free radicals formed during the oxidative process ${ }^{21}$.

According to Yeh et al. ${ }^{29}$, phenolic acids act as inducers of antioxidant enzymes gene expression. Genistic acid, ferulic acid, gallic acid, and $p$ coumaric acid increased mRNA expression of cardiac CuZn-SOD, GPx, and CAT in the heart and hepatic tissues, as well as the level of the respective enzyme activity and the total antioxidant capacity in rats. Arcari ${ }^{30}$ examined the biological effects of mate tea consumption (Ilex paraguariensis) against obesity in rats, and if the obesity and amendment with Ilex paraguariensis may modulate the expression of genes involved in the production phase II enzymes antioxidants, such as SOD, CAT and GPx, published different results to those found in this study. The data revealed that there was no change in any of the different groups studied after the supplementation with Ilex paraguariensis.

On the other hand, Matsumoto et al. ${ }^{31}$, studied in healthy women who ingested Ilex paraguariensis infusion for one week, and there was a significant increase in the expression of the GSH-Px antioxidant enzyme, which catalyzes the reduction of $\mathrm{H}_{2} \mathrm{O}_{2}$ and organic peroxides in $\mathrm{H}_{2} \mathrm{O}$ and their respective alcohols from the oxidation of GSH to oxidized glutathione.

The capacity of mate tea to neutralize ROS is attributed to caffeoylquinic compounds. Chlorogenic acids (3-CQA) have been extensively studied due to their free radical and metal scavenging capacity, and the ability to modulate gene expression of antioxidant enzymes ${ }^{32}$. The capacity of mate tea in reducing oxidative damage is not only associated with ability to neutralize ROS, but also improves the antioxidant defense enzymes ${ }^{33}$, promoted by increased gene expression of SOD, CAT and GPx ${ }^{34}$.

Another very important fact in the study of Ilex paraguariensis relates to the polyphenols which can exert antioxidant ability to neutralize ROS, but this protection may occur through endogenous antioxidant activity, increased expression of antioxidant enzymes in coenzyme cells S7 (COS7). One possible mechanisms of these phytochemicals is involved in the modulation of gene expression of antioxidant enzymes, which assists in the removal of carcinogens and harmful toxins into the body, such as the lipoperoxides, thereby preventing the interaction with macromolecules (proteins, lipids and DNA) which could cause mutations and culminate the appearance of cancers ${ }^{35}$.

Many of the metabolic regulatory pathways are deranged in models using high-fat diets ${ }^{36}$. A high-fat diet promotes an increased supply of triglycerides and fatty acids and consequently an increase of fatty acids oxidation as a way to get energy. Excessive consumption of fats, as in obesity, increases mitochondrial oxidative work load, which causes an increase in mitochondrial ROS production by the electron transport chain and, 
consequently, the oxidative stress situation ${ }^{37}$. De Paula et al. ${ }^{36}$ suggest that the increased oxidative stress is directly related to the change in the diet.

Increased oxidative stress in accumulated fat is an important pathogenic mechanism of metabolic syndromes associated with obesity, because oxidative damage may favor cell damage and inflammatory processes ${ }^{38}$. As a compensatory response to the damage, there is an increase in the activity of antioxidant enzymes CAT, SOD e GPx and, in addition to this, there is a tendency to increase gene expression of these enzymes. De Paula et al. ${ }^{36}$ reported that the increase in the activity and expression of antioxidant enzymes may represent a compensatory response to oxidative insults of the high-fat diet.

\section{CONCLUSIONS}

According to the results from this study, it can be inferred that the Ilex paraguariensis decreased the lipid peroxidation in the animals treated with standard diet. It was also shown an increase in antioxidant potential of the GSH endogenous enzyme activity in the hippocampus of the animals when treated with high-fat diet and Ilex paraguariensis. Likewise, it was shown an increased on gene expression of SOD, CAT and GPx in the liver when rats were supplemented with high-fat diet and Ilex paraguariensis. It was also shown that the animals treated with high-fat diet and without Ilex paraguariensis reduced the expression of the SOD and CAT enzyme. In summary, the Ilex paraguariensis showed substantial potential for antioxidant activitys.

\section{ACKNOWLEDGMENTS}

This study was financed in part by the Coordenação de Aperfeiçoamento de Pessoal de Nível Superior - Brasil (CAPES) - Finance Code 001. Authors thank also the financial support of the Brazilian agencies: Conselho Nacional de Desenvolvimento Científico e Tecnológico - Brasil (CNPq) and Fundação de Amparo à Pesquisa do Estado do Rio Grande do Sul - Brasil (FAPERGS).

\section{CONFLICT OF INTEREST}

The authors declare no conflict of interest.

\section{REFERENCES}

1. Shinde A, Ganu J, Naik P. Effect of free radicals \& antioxidants on oxidative stress: a review. J Dental Allied Sci. 2012; 1: 63-66.

2. Birben E, Sahiner UM, Sackesen C, Erzurum S, Kalayci O. Oxidative stress and antioxidant defense. World Allergy Org J. 2012; 5: 9-19.

3. Young IS, Woodside JV. Antioxidants in health and disease. J. Clin. Pathol. 54: 176-186 (2001)

4. Bajpai VK, Sharma A, Kang SC, Baek KH. Antioxidant, lipid peroxidation inhibition and free radical scavenging efficacy of a diterpenoid compound sugiol isolated from Metasequoia glyptostroboides. Asian Pac J Trop Med. 2014; 7: 9-15.

5. Korir MW, Wachira FN, Wanyoko JK, Ngure RM, Khalid R. The fortification of tea with sweeteners and milk and its effect on in vitro antioxidant potential of tea product and glutathione levels in an animal model. Food Chem. 2014; 145: 145153. 
6. Zenaro LC, Andrade LB, Santos P, Locatelli C. Effects of aqueous extract of yerba mate (Ilex paraguariensis) on the oxidative stress in rats fed a cafeteria diet. Int J Nat Sci Res. 2: 30-43 (2014)

7. Bracesco N, Sanchez AG, Contreras V, Menini T, Gugliucci A. Recent advances on Ilex paraguariensis research: minireview. J Ethnopharmacol. 2011; 136: 378384.

8. Balzan S, Hernandes A, Reichert CL, Donaduzzi C, Pires VA, Junior AG, et al. Lipid-lowering effects of standardized extracts of Ilex paraguariensis in high-fatdiet rats. Fitoterapia. 2013; 86: 115-122.

9. Reeves PG, Nielsen FH, Fahey GC. AIN- 93 purified diets for laboratory rodents, final report of the American Institute of Nutrition Ad Hoe Writing Commitee on the Reformulation of AIN-76A. J Nutr. 1993; 123:1939-1951.

10. Cobea. Ethical principles for animal experimentation. 2008. [Avaliable at: <http://www.cobea.org.br>]. Accessed on: July 7, 2016.

11. Esterbauer H, Cheeseman KH. Determination of aldehydic lipid peroxidation products: malonaldehyde and 4-hydroxynonenal. Methods Enzymol. 1990; 186: 407421.

12. Browne RW, Armstrong D. Reduced glutathione and glutathione disulfide. Methods Mol Biol. 1998; 108: 347-352.

13. Masternak MM, Al-Regaiey KA, Del Rosario Lim MM, Bonkowski MS, Panici JA, Przybylski GK, et al. Caloric restriction results in decreased expression of peroxisome proliferator-activated receptor superfamily in muscle of normal and long-lived growth hormone receptor/binding protein knockout mice. J Gerontol A Biol Sci Med Sci. 2005; 60: 1238-1245.

14. Amin KA, Kamel HH, Eltawab MAA. The relation of high fat diet, metabolic disturbances and brain oxidative dysfunction: modulation by hydroxy citric acid. Lipids Health Dis. 2011; 10: 1-11.

15. Bhat AH, Dar KB, Anees S, Zargar MA, Masood A, Sofi MA Ganie SA. Oxidative stress, mitochondrial dysfunction and neurodegenerative diseases; a mechanistic insight. Biomed Pharmacother. 2015; 74:101-110.

16. Birben E, Sahiner UM, Sackesen C, Erzurum S, KalayciO. Oxidative stress and antioxidant defense. World Allergy Organ J. 2012; 5: 9-19.

17. Park HR, Park M, Choi J, Park KY, Chung HY, Lee J. A high-fat diet impairs neurogenesis: Involvement of lipid peroxidation and brain-derived neurotrophic factor. Neurosc. Lett. 2010; 482: 235-239.

18. Key TJ. Fruit and vegetables and cancer risk. Brit J Cancer. 2011; 104: 6-11.

19. Scolaro B, Lima DD, Cruz JGP, Delwing-DalMagro D. Mate tea prevents oxidative stress in the blood and hippocampus of rats with acute or chronic ethanol administration. Oxidative Med Cel Longevity. 2012; 1: 1-8.

20. Anesini C, Turner S, Cogoi L, Filip R. Study of the participation of caffeine and polyphenols on the overall antioxidant activity of mate (Ilex paraguariensis). LWTFood Sci Technol. 2012; 45: 299-304.

21. Gugliucci A, Stahl AJ. Low density lipoprotein oxidation is inhibited by extracts of Ilex paraguariensis. Biochem Mol Biol Int. 1995; 35: 47-56.

22. Haddad JJ, Harb HL. L-gamma-glutamyl-l-cysteinyl-glycine (glutathione; GSH) and GSH-related enzymes in the regulation of pro- and anti-in- flammatory cytokines: a signaling transcriptional scenario for redox (y) immunologic sensor(s)?. Mol Immunol. 2005; 42: 987-1014.

23. Espinosa-Diez C, Miguel V, Mennerich D, Kietzmann T, Sánchez-Pérez P, Cadenas S, et al. Antioxidant responses and cellular adjustments to oxidative stress. Redox Biol. 6:183-197 (2015)

24. Kim SY, Oh MR, Kim MG, Chae HJ, Chae SW. Anti-obesity effects of Yerba Mate (Ilex paraguariensis): a randomized, double-blind, placebo-controlled clinical trial. BMC Complement Altern Med. 2015; 15: 1-8.

25. Bravo L, Mateos R, Sarriá B, Baeza G, Lecumberri E, Ramos S, et al. Hypocholesterolaemic and antioxidant effects of yerba mate (Ilex paraguariensis) in high-cholesterol fed rats. Fitoterapia. 2014; 92: 219-229. 
26. Lahouel M, Boutabet K, Kebsa W, Alyane M. Polyphenolic fractions of algerian propolis reverses doxorubicin induced acute renal oxidative stress. Afr J Pharm Pharmacol. 2010; 4: 712-720.

27. Boaventura BC, Di Pietro PF, Stefanuto A, Klein GA, de Morais EC, de Andrade $\mathrm{F}$, et al. Association of mate tea (Ilex paraguariensis) intake and dietary intervention and effects on oxidative stress biomarkers of dyslipidemic subjects. Nutrition. 2012; 28: 657-664.

28. Morais EC, Stefanuto A, Klein GA, Boaventura BCB, de Andrade F, Wazlawik $\mathrm{E}$, et al. Consumption of yerba mate (Ilex paraguariensis) improves serum lipid parameters in healthy dyslipidemic subjects and provides an additional LDLcholesterol reduction in individuals on statin therapy. J Agric Food Chem. 2009; 57: 8316-8324.

29. Yeh CT, Ching LC, Yen GC. Inducing gene expression of cardiac antioxidant enzymes by dietary phenolic acids in rats. J Nutr Biochem. 2009; 20: 163-171.

30. Arcari DP, Bartchewsky W, Dos Santos TW, Oliveira KA, Funck A, Pedrazzoli $\mathrm{J}$, et al. Antiobesity effects of yerba mate extract (Ilex paraguariensis) in high-fat diet-induced obese mice. Obesity. 2009; 17: 2127-2133.

31. Matsumoto RL, Bastos DH, Mendonça S, Nunes VS, Bartchewsky W, Ribeiro $\mathrm{ML}$, et al. Effects of mate tea (Ilex paraguariensis) ingestion on mRNA expression of antioxidant enzymes, lipid peroxidation, and total antioxidant status in healthy young women. J Agric Food Chem. 2009; 57: 1775-1780.

32. Jaiswal R, Sovdat T, Vivan F, Kuhnert N. Profiling and characterization by LCMS(n) of the chlorogenic acids and hydroxycinnamoylshikimate esters in mate (Ilex paraguariensis). J Agric Food Chem. 2010; 58: 5471-84.

33. Boaventura BC, Di Pietro PF, Stefanuto A, Klein GA, de Morais EC, de Andrade F, Wazlawik E, da Silva EL. Association of mate tea (Ilex paraguariensis) intake and dietary intervention and effects on oxidative stress biomarkers of dyslipidemic subjects. Nutr J. 2012; 28: 657-664.

34. Bracesco NA, Sanchez G, Contreras V, Menini T, Gugliucci A. Recent advances on Ilex paraguariensis research: minireview. J Ethnopharmacol. 2011; 136: 378384.

35. Filip R, Sebastian T, Ferraro G, Anesini C. Effect of Ilex extracts and isolated compounds on peroxidase secretion of rat submandibulary glands. Food Chem Toxicol. 2007; 45: 649-655.

36. De Paula MT, Silva MRP, Araujo SM, Bortolotto VC, Meichtry LB, Zemolin APP, Wallau GL, Jesse CR, Franco JL, Posser T, Prigol M. High-Fat Diet Induces Oxidative Stress and MPK2 and HSP83 Gene Expression in Drosophila melanogaster. Oxid Med Cell Longev. 2016; 1: 1-12.

37. Semenkovich CF. Insulin resistance and atherosclerosis. J Clin Invest. 2006; 116: 1813-1822.

38. Furukawa S, Fujita T, Shimabukuro M, Iwaki M, Yamada Y, Nakajima Y, Nakayama O, Makishima M, Matsuda M, Shimomura I. ncreased oxidative stress in obesity and its impact on metabolic syndrome. J Clin Invest. 2004; 114: 1752-1761. 